\title{
Bye Bye
}

Peer-Reviewed Publishing

\author{
M. Abambres $\underline{\mathrm{GS}}$, email T. Salloom $\underline{\mathrm{RG}}$ N. Beganovic $\underline{\mathrm{RG}}$ \\ R. Dojka $\underline{\mathrm{RG}}, \underline{\mathrm{GS}}$, email S. Roncallo-Dow $\underline{\mathrm{RG}} \mathrm{S}$. Takhar $\underline{\mathrm{RG}}$ \\ T. Verma $\underline{\mathrm{RG}}, \underline{\mathrm{GS}}$, email
}

Co-Authorship Invitation: Anyone supporting all ideas presented in this manuscript can become co-author without adding any content. This is perfectly OK for me, since this is an opinion paper, and thus the more it is disseminated, the more likely those ideas are made real in a near future. If you want me to add you as co-author, please send me your name and affiliation by email.

(C) 2019 by Abambres et al. (CC BY 4.0)

ID: hal-02114531

\begin{abstract}
This work is the continuation of a 'revolution' started with Research Counts, Not the Journal. Own and published opinions from worldwide scientists on critical issues of peer-reviewed publishing are presented. In my opinion, peer-reviewed publishing is a quite flawed process (in many ways) that has greatly harmed Science for a long time - it has been imposed by most academic and science funding institutions as the only way to assess scientific performance. Unfortunately, most academics still follow that path, even though I believe most do it for the fear of losing their job or not being promoted. This paper aims to encourage (i) a full disruption of peer-reviewed publishing and (ii) the use of free eprint repositories for a sustainable academic/scientific publishing, i.e. healthier (no stress/distress associated to the peer review stage and the long waiting for publication) and more economic, effective and efficient (research is made immediately available and trackable/citable to anyone). On the other hand, it should be pointed out that nothing exists against scientific publishers/journals - actually it's perfectly normal that any company wants to implement its own quality criteria. This paper is just the way chosen to promote the quick implementation of suitable policies for research evaluation.
\end{abstract}

Keywords: Science, Research, Scientific Publishing, Journals, Articles, Papers, Preprints, Eprints, Open Science, Peer Review, Pre-Publication Peer Review, Post-Publication Peer Review, PPPR, Reviewers, Editors, Publishers, Scientific Institutions, Science Funding, Academic Institutions, Universities, Academia, Scientific Evaluation, Scientific Impact, Scientific Performance, Scientific Assessment, Research Quality, Sustainability, Sustainable Science, Scientific Revolution. 
ID: hal-02114531

(C) 2019 by Abambres et al. (CC BY 4.0)

\section{Why I Really Don`t Care About Peer Review}

In traditional scientific journals (still the greatest amount available), any paper first gatekeeper is the managing or scientific editor. The articles overcoming that hurdle are sent out to 2 to 4 "experts" in the field (also called peers or reviewers), who are asked to provide in an independent way their views on (i) the quality of the paper and (ii) whether or not it should be accepted for publication in that journal ('major-revisions and re-submission required' is an intermediate verdict often allowed). Once the scientific editor gets all reviews, her/his final decision on the paper acceptance is formulated and communicated to the authors. This is the traditional and widely implemented (pre-publication) peer review. In my opinion, peer-reviewed publishing is a quite flawed process that has greatly harmed Science for a long time - it has been imposed by most academic and science funding institutions as the only way to assess scientific performance. Unfortunately, most academics still follow that path, even though I believe most do it for the fear of losing their job or not being promoted. Why, for me, doesn't peer-reviewed publishing make any sense, and is a waste of my precious time and health?

i. Would you cite some peer-reviewed work without going through it yourself to make sure the facts you are citing are correct/reliable? If yes, that's awful in my opinion. If not, then what you need peer review for? For me, peer review is naturally carried out by each reader of a publication - there's no other way to do it!

ii. Researchers (such as myself) invited many times by Scopus- or SCIE-indexed journals ${ }^{1}$ to review papers, are simultaneously those (i) whom the editors take "as God" (reviewers) in order to make decisions on whether or not to publish somebody else's paper, and (ii) whose works are often rejected for publication by those journals.

1. The most "renowned" databases of scientific journals are Scopus and Science Citation Index Expanded (SCIE, popularly known as ISI), being the latter the most important for most academic/scientific institutions nowadays. 


\section{ID: hal-02114531}

(C) 2019 by Abambres et al. (CC BY 4.0)

iii. Recently, while checking the comments of 3 reviewers for a paper of mine, I realized the negative judgements were unique from each reviewer, i.e. the negative points highlighted by each one were not negative for the remaining experts. As you see, reviewing is far from being a fully objective process. Why should editors rely on the diverse opinions of 2 to 4 people they don't even know personally nor can guarantee to be fully honest? In Science, as in all other professions, there is competition to a certain extent, and if reviewers are said to be experts in the subject of the paper, its authors might be direct competitors of the reviewers.

iv. The web is full of stories about flawed and/or fraudulent peer review (e.g., Haug 2015, O'Grady 2017); for instance:

- Peters and Ceci (1982) described a study in which two researchers selected 12 articles already accepted 18 to 32 months ago by top tier journals, swapped the real names and affiliations for false ones, and resubmitted the identical material to the same journals. Of the nine papers that continued through the review process, eight were turned down with $89 \%$ of reviewers recommending rejection (Carroll 2018).

- $\mathrm{A} \mathrm{BMJ}{ }^{2}$ article deliberately inserted eight errors into a 600 -word report of study about to be published and then sent it to 300 reviewers. The median number of errors spotted was two, and $20 \%$ of reviewers did not spot any errors (Smith 2010).

v. Editors typically "impose" a 3-5-week deadline to reviewers, but most (editors and reviewers) just don't care about it (note that reviewers are not paid for their job). It might even happen that editors are "forced" to invite new reviewers to replace those who stopped giving feedback or take too long to send their review. Thus, the review process (since submission until editor's decision is communicated) can often take more than 4 months (6 months for the online publication, if the paper

2. A renowned peer-reviewed medical journal, originally called British Medical Journal. 
ID: hal-02114531

(C) 2019 by Abambres et al. (CC BY 4.0)

is accepted ${ }^{3}$ ). Besides, there's a substantial risk that reviewers either reject the paper or request "improvements" that you refuse to implement (they might be scientifically wrong, fully irrelevant, or even ridiculous), as happened to me $95 \%$ of the time since $2018^{4}$.

- If the paper is not published and you pick another traditional peer-reviewed journal to try to finally publish your work, you'll face another similar waiting round (besides the need for reformatting the paper every time the new journal imposes distinct submission guidelines, even though many have already adopted a format-free policy ${ }^{5}$ ).

vi. Editors reject innovative (never published before) papers with no scientific/technical errors just because the authors refuse to include the analyses / results / figures requested by 2 to 4 reviewers (like those reviewers were the authors of the paper).

vii. Some journals want to impose "their review", not accepting the reviews from who they invited themselves for that job. Some seem also not to accept reviews where no improvements to the submitted manuscript are requested. After reviewing a paper for a SCIE-indexed journal, the managing editor sent me the following email:

3. It's not unheard of for papers to take a year or more to get out of the lab and into the world, even in the digital age. Scientific publication through journals has become more about earning prestige points to advance your career than communicating new findings (Curry 2015).

4. If that happens and you are loyal to your values and ideas, the right thing to do in my opinion is to withdraw the submission and try to publish your work elsewhere.

5. However, Elsevier (one of the major scientific publishers worldwide) makes it clear that this policy is only valid for the submission stage. Once the paper is accepted for publication, the authors are required to resubmit it following the journal formatting guidelines, so that it can be further edited and lastly published. In my opinion, it makes no sense at all - any format-related task should be a publisher duty only. 
ID: hal-02114531

(C) 2019 by Abambres et al. (CC BY 4.0)

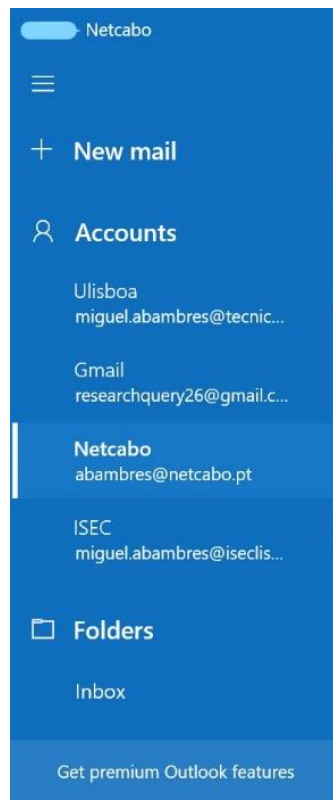

$\square$ 圆 $\Omega^{Q} \otimes$ 的

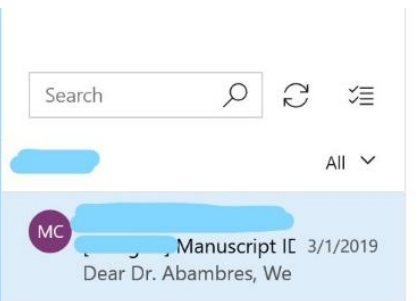

Friday, November 2, 2018

( info@preprints.org Response to screen pre 11/2/2018 Dear Miguel Abambre:

Thursday, November 1, 2018

(1)info@preprints.org > Re: headshot 11/1/2018 Dear Dr. Abambres, AfI

Thursday, October 25, 2018

SY Selina Yang

> [Publications] Mani 10/25/2018 Dear Dr. Lantsoght, Tr

Monday, October 15, 2018
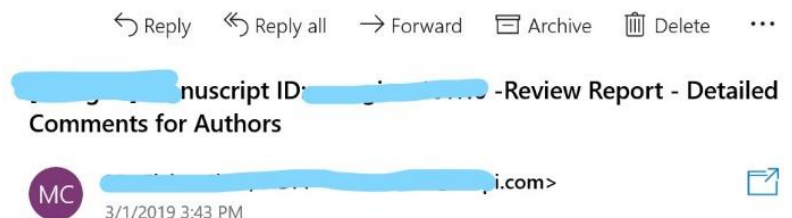

3/1/2019 3:43 PM

To: abambres@netcabo.pt Cc. Pricom

Dear Dr. Abambres,

We really appreciate your comments for this manuscript. However, we notice that you recommend the acceptance of this manuscript at current form. Could you please provide some detailed comments for the authors to improve their manuscript (from language or technical aspect)? We hope you can spare some time reorganizing your comments as follows:

1. Briefly summarize the content of the manuscript;

2. Illustrate what are, in your opinion, the manuscript's strengths and weaknesses [this is an essential step, because the Editor will consider the reasoning behind your recommendation and needs to understand it properly];

3. Provide a point-by-point list of your major recommendations for the improvement of the manuscript;

4. If necessary, provide a point-by-point list of your minor for the

improvement of the manuscript.

You may send the detailed comments to me by email, and I will help to

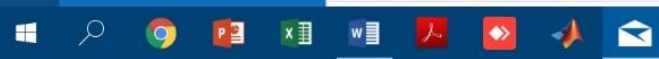

The longer you take to ignore harmful policies and people in science/academia, the longer you and your beloved ones will have to wait to be truly happy as academics ... Don't be a slave of any system - be loyal to your professional values and dignity!

\section{Further Opinions on Peer Review}

Arguments against classical peer review generally come in two forms, that it wrongly (i) rejects scientifically valid papers, and (ii) accepts scientifically flawed papers (IDEAC 2019). Next, many opinions from scientists on the issues of traditional peer review are provided, as published in the literature since 1977. 
ID: hal-02114531

(C) 2019 by Abambres et al. (CC BY 4.0)

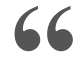

The peer review system is arguably better at one thing above all others: censorship - from contrarian viewpoints to innovations that render favored dogmas obsolete (economic threats).

The neophobia in the world of science serves to protect the status quo rather than improve knowledge.

Scientists have often fairly hefty egos. Once those egos rise to positions of power and/or influence, they can calcify the flow of scientific progress - particularly if they end up acting as peer reviewers in prestigious publications. 
ID: hal-02114531

(C) 2019 by Abambres et al. (CC BY 4.0)

\section{6}

Scientists publishing non-peer-reviewed papers do not engage in quick posting of low-quality work because they are wary of developing a bad reputation in the community. Furthermore, if the work is poor, then it will likely just be ignored by the rest of the community.

Polka (2019) 
ID: hal-02114531

(C) 2019 by Abambres et al. (CC BY 4.0)

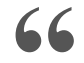

As an author, I am often amazed by the reviews that I receive. Some offer tangential ideas that have little to do with the manuscript, presumably to show that they thought about the subject. Others insist that their own work be cited ${ }^{6}$.

Regardless of the insanity of any individual comment, the authors must respectfully (often obsequiously) embrace each sentence and thank the reviewer for it. All too often, in their zeal to please the reviewers, the authors revise the paper in a way that makes it much worse than the original ${ }^{6}$.

The peer review process is horribly broken.

Packer (2019)

6. Happened to me most of the time since 2018, but from now on I am not disseminating my papers via peer-reviewed journals anymore. The only exception is when my co-authors "have to" do it because they like it or fear (as explained in section 1) to abandon that system - in that case (i) they are the corresponding authors (I refuse to get in touch with editors and reviewers belonging to a flawed and fraudulent system), and (ii) I will make it clear in the 'contributions' section of the paper that those changes to the original manuscript were not my contribution. 
ID: hal-02114531

(C) 2019 by Abambres et al. (CC BY 4.0)

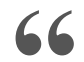

The peer review system is deeply wrong.

A third objection is that the system is fundamentally conservative. Since the judgments are asked from people established in a field, these may not welcome innovations that can potentially challenge their fixed views.

I have often seen comments of the order of

'why doesn't the author quote so-and-so,

a major figure in the field?'

Bal (2018) 
ID: hal-02114531

(C) 2019 by Abambres et al. (CC BY 4.0)

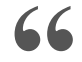

Pre-publication peer review is far from fair and objective. There is clearly a subjective element to reviewing a scientific paper. Reviewers and editors are not always qualified or free of bias. Senior investigators may be given a "free pass" because of their reputation in the field, and the work from new investigators is usually examined with much closer scrutiny.

Gender bias is another shameful problem plaguing the review process.

99

Sullivan (2018) 
Actually, in my opinion, those somehow renowned scientists who (i) are the last author of most of their papers, (ii) have tens of students working for them, and (iii) rarely put their hands on real research work ${ }^{7}$ when dealing with non-opinion papers (their job is mostly giving some ideas and/or reviewing the manuscript written by their co-authors), are likely to be against abandoning peer review. Why?

- Without the requirement of peer reviewing for the trustworthiness of published research, early career scientists wouldn't have to depend so much on the aforementioned renowned scientists to publish their work quickly and in a reliable way. Thus, the productivity of those senior "scientists" (not real scientists for $\mathrm{me}^{8}$ ) would fall abruptly.

Even in the field of research management, I wouldn't say the senior scientists described above are a model to follow, due to the large amount of $\mathrm{PhD}$ students they usually "supervise". If I were a $\mathrm{PhD}$ supervisor I wouldn't accept having more than three doctoral students in their first three years of research.

- Supervising is not just answering students' questions or telling them where to search those answers. Most of all is being able to create empathy and to make students scientifically independent and passionate about science in general. But creating real empathy is a timedemanding task not compatible with busy and anxious people.

7. e.g., literature reviewing, programming, using commercial analysis software, formulation development, computations, carrying out part (at least) of the experimental work, observing and analyzing in the field, collecting data.

8. For me, a real scientist must have a relevant part of published work carried out by him/herself - only that way one can really master an area of knowledge. 
ID: hal-02114531

(C) 2019 by Abambres et al. (CC BY 4.0)

66

Post-Publication Peer Review (PPPR) can become a new cornerstone in the self-correcting mechanism of Science. 
ID: hal-02114531

(C) 2019 by Abambres et al. (CC BY 4.0)

\section{6}

Peer review is by no means perfect. It is itself subject to bias, as most things in research are. 
ID: hal-02114531

(C) 2019 by Abambres et al. (CC BY 4.0)

\section{6}

There is evidence that reviewers are not always consistent. As an author of papers, and as a writer who comments on papers in the news media, I've seen how the peer review process can fail. 
ID: hal-02114531

(C) 2019 by Abambres et al. (CC BY 4.0)

66

bioRxiv, the pre-print server for biology ${ }^{9}$, has transformed how we disseminate our science. Papers are available immediately and we obtain valuable feedback from the community. This instantly depressurizes the relationship between author and journal. We are no longer held hostage by the journals.

Vosshall (2018)

9. Operated by Cold Spring Harbor Laboratory, a private not-for-profit research and educational institution founded in 1890, home to eight Nobel Prize winners so far. 
ID: hal-02114531

(C) 2019 by Abambres et al. (CC BY 4.0)

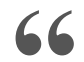

Nowadays, there are many scientists who question the value and effectiveness of the actual peer review process. According to them, the negative aspects of peer review far outweigh its benefits.

Some peer review opponents suggest that peer review also causes the suppression of some scientists' results. A reviewer who is examining the paper might reject research that conflicts with his own findings or points of view. 
ID: hal-02114531

(C) 2019 by Abambres et al. (CC BY 4.0)

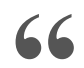

Authors must stand behind their submitted preprint... Even without peer review, their scientific colleagues will be reading and judging the work, and the authors' reputations are at stake...Thus,... work of low quality would not be expected. This has been true of arXiv (owned by Cornell University) over the years, and the high-quality factor also seems to apply to bioRxiv ${ }^{10}$.

Bourne et al. (2017) 
ID: hal-02114531

(C) 2019 by Abambres et al. (CC BY 4.0)

\section{6}

We should skip the current peer review system, we should just publish through the internet - when it's important it should be reviewed by thousands of scientists anyway, immediately, and when something bad is there it should be revealed, very quickly (video). 
ID: hal-02114531

(C) 2019 by Abambres et al. (CC BY 4.0)

\section{6}

Science should not, and need not, be shackled by journal publication.

This murky process is prone to abuse. At its worst, cabals of researchers are suspected of guaranteeing favourable reviews for each other's work.

A handful of firms are using artificial intelligence to assess the scientific importance of research, irrespective of how it has been disseminated. Such approaches ${ }^{11}$ need encouragement. 
ID: hal-02114531

(C) 2019 by Abambres et al. (CC BY 4.0)

\section{6}

The trouble is the traditional journal-based peer review system is demonstrably flawed, with failure to uphold the integrity of the Science at several steps in the publishing process. 
ID: hal-02114531

(C) 2019 by Abambres et al. (CC BY 4.0)

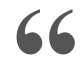

Peer review can slow publication of articles, its operational costs increase the cost of publication, and it is burdensome on reviewers' time. Given criticisms of how effective peer review is, some have argued that Science would be better-off if peer review was abandoned. Ultimately it is future observation and experimentation that will demonstrate whether the study was right. Therefore, it might be argued, why try to guarantee the validity of what is published? Just disseminate the paper and let the progress of Science determine what stands and falls.

Etkin et al. (2017) 
ID: hal-02114531

(C) 2019 by Abambres et al. (CC BY 4.0)

66

For some scientists, the term is now a misnomer - their preprint papers will never be submitted for formal publication - e.g., Graham Coop, an evolutionary geneticist at the University of California (Davis), took to social media to state that one of his bioRxiv preprints is the final version. 
ID: hal-02114531

(C) 2019 by Abambres et al. (CC BY 4.0)

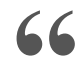

Researchers are increasingly questioning the time it takes to publish their work. Many say that they feel trapped in a cycle of submission, rejection, review, re-review and re-re-review that seems to eat up months of their lives, interfere with job, grant and tenure applications...

Many scientists say that reviewers are requesting more data, revisions and new experiments than they used to - we are demanding more and more unreasonable things from each other.

Powell (2016) 
ID: hal-02114531

(C) 2019 by Abambres et al. (CC BY 4.0)

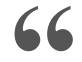

There are at least nine deficiencies in the current model that are fueling a sense that journals as we have known them are approaching their final act, such as: too slow, too expensive, too limited, too unreliable, too focused on the wrong metrics, too parochial, too powerful.

Journals tend to lack diversity in their editorial groups. This issue is true with regard to sex and race/ethnicity, as well as national origin. Science knows no national boundaries, yet journals seem to have national, and sometimes even regional, preferences with regard to their selection of submissions. 
ID: hal-02114531

(C) 2019 by Abambres et al. (CC BY 4.0)

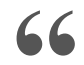

Reviews too often also reveal the darker human impulses at work within the research community - ego, jealousy, ignorance and laziness.

Every researcher I know has at least one tale of woe about their experiences at the hands of unreasonable or incompetent peer reviewers.

The most selective journals are also those with the highest rates of retractions (papers deleted from the published literature due to serious errors or fraud ${ }^{12}$ ).

There is a growing concern that the results of many peer-reviewed studies cannot be reproduced - supposedly the benchmark for good science. 
ID: hal-02114531

(C) 2019 by Abambres et al. (CC BY 4.0)

66

Scientific publishing is riddled with problems.

Rutherford (2015) 
ID: hal-02114531

(C) 2019 by Abambres et al. (CC BY 4.0)

66

For some, there is a reason to get rid of peer review. Brandon Stell, the president of the PubPeer Foundation, favors post-publication peer review on websites like his own. There, users from around the world can critique and comment on articles that have already been published. These crowdsourced comments have led to corrections or even retractions of studies.

Belluz and Hoffman (2015) 
ID: hal-02114531

(C) 2019 by Abambres et al. (CC BY 4.0)

\section{6}

Institutions have to judge the quality of a person based on the quality of the research... you shouldn't be relying on journals and two or three reviewers to judge that - you have to do that yourself... some people are not publishing in the highest profile journals because they are in advance of everybody else (video). 
ID: hal-02114531

(C) 2019 by Abambres et al. (CC BY 4.0)

\section{6}

It is alarming that so many Nobel Prize recipients have lamented that they would never have survived this current academic environment. 
ID: hal-02114531

(C) 2019 by Abambres et al. (CC BY 4.0)

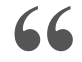

So, you know we now have these performance criteria, which I think are just ridiculous in many ways. And of course, all the academics say we've got to have peer review. But I don't believe in peer review because I think it's very distorted.

I think peer review is hindering science. In fact, I think it has become a completely corrupt system. It's corrupted in many ways, in that scientists and academics have handed over to the editors of these journals the ability to make judgment on science and scientists...and that's all been done in the aid of commerce, because they are now giant organisations making money out of it.

Brenner (2014)

Nobel Laureate

(in Dzeng 2014) 
There is a growing movement that wants to retort as Albert Einstein did to such a review process. The reviewer of the first and only Einstein's paper sent to anonymous peer review returned ten pages of comments, then sent to Einstein by the editor, who asked him to consider the issues, and make any changes he saw necessary. Einstein's reaction: We had sent you our manuscript for publication and had not authorized you to show it to specialists before it is printed. I see no reason to address the - in any case erroneous - comments of your anonymous expert. On the basis of this incident I prefer to publish the paper elsewhere.

Many of the core scientific discoveries were not peer reviewed to modern standards. For example, the foundational paper describing the double helical structure of DNA, by Watson and Crick in 1953, would have been jeopardized in the context of the classic review system as we know it, because of its speculative nature.

Some think that the peer review system should be abandoned in favor of a 'market of ideas' where the best research would naturally be identified by the crowd, hence reducing the cost of the review process. 
ID: hal-02114531

(C) 2019 by Abambres et al. (CC BY 4.0)

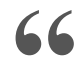

Using a dataset of 1,008 manuscripts submitted to three elite medical journals, we show differences in citation outcomes for articles that received different appraisals from editors and peer reviewers. Of the 808 published articles in our dataset (not necessarily on those three elite journals), our three focal journals rejected many highly cited manuscripts, including the 14 most popular; roughly the top 2 percent. Of those 14 articles, 12 were desk-rejected (deemed not even worthy of peer review by the editor). This finding raises concerns regarding whether peer review is ill-suited to recognize and gestate the most impactful ideas and research. 
ID: hal-02114531

(C) 2019 by Abambres et al. (CC BY 4.0)

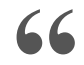

It is foolish to view the published result as the only thing that counts simply because it was published. Science is not like soccer. In soccer a match result stands even if it is the product of a blatantly wrong referee call (e.g., a decision not to award a goal even though the ball was completely past the goal line). Science doesn't work this way. We need to have a solid foundation of our scientific knowledge. We simply cannot say that once a paper is "in", the results ought to be believed. Replication and community-based review are two tools at our disposal for continuously checking the structural integrity of research. 
ID: hal-02114531

(C) 2019 by Abambres et al. (CC BY 4.0)

66

The editorial process can be so protracted, with so many requirements, that you end up with a paper which is totally unreadable...you have no idea what it's about or what these people are trying to say - the reviewers have turned it into a porridge! You don't wanna publish porridge! (video)

Doherty (2012)

Nobel Laureate 
ID: hal-02114531

(C) 2019 by Abambres et al. (CC BY 4.0)

\section{6}

The traditional publication system restricts the access to papers by requiring payment, and it restricts the evaluation of papers by relying on just 2-4 pre-publication peer reviews and by keeping the reviews secret...The benefit of publishing all papers may outweigh the cost of providing the necessary storage and access. "Publish, then filter" is one of the central principles that lend the web its power (Shirky 2008).

Kriegeskorte et al. (2012) 
ID: hal-02114531

(C) 2019 by Abambres et al. (CC BY 4.0)

\section{6}

Peer review is broken. We have all heard that phrase many times in recent years. It's become a truism, a shorthand complaint about the status quo that rarely extends into a proposal for change. And even those who do not believe standard peer review is beyond repair acknowledge that there are problems; everyone can see the cracks.

Peer review is almost always secret; authors do not know who is reviewing their work - perhaps an ally but, equally, perhaps a competitor. It can block ingenuity... 
ID: hal-02114531

(C) 2019 by Abambres et al. (CC BY 4.0)

\section{6}

Let every man judge according to his own standards, by what he has himself read, not by what others tell him.

\section{Einstein}

(in Einstein et al. 2011) 
ID: hal-02114531

(C) 2019 by Abambres et al. (CC BY 4.0)

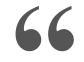

The public has been trained to accept as established truth any science that has gone through the gauntlet of peer review. But the truth is that peer review as practiced in the 21st century biomedical research poisons science. It is conservative, cumbersome, capricious and intrusive.

The peer reviewed literature is filled with all manner of crappy papers. And even the supposedly more rigorous standards of the elite journals fail to prevent flawed papers from being published. 
ID: hal-02114531

(C) 2019 by Abambres et al. (CC BY 4.0)

66

The US National Library of Medicine indexes 39 journals that deal with alternative medicine. They are all peer-reviewed, but rarely publish anything worth reading.

There is an alternative: publish your paper yourself on the web and open the comments.

Colquhoun (2011) 
ID: hal-02114531

(C) 2019 by Abambres et al. (CC BY 4.0)

\section{6}

In reality, the reviewers who are experts in the subfield of a paper often have some personal stake in the paper's publication. They may be invested in the theory supported or in another theory. More generally, they may have competitive feelings that compromise their objectivity. 
ID: hal-02114531

(C) 2019 by Abambres et al. (CC BY 4.0)

66

We have little evidence on the effectiveness of peer review, but considerable evidence on its defects. In addition to being poor at detecting gross defects and almost useless for detecting fraud, it is slow, expensive, profligate of academic time, highly subjective / inconsistent, prone to bias, and easily abused.

There are several ways to abuse the process of peer review. You can steal ideas and present them as your own or produce an unjustly harsh review to block (or at least slow down) the publication of the ideas of a competitor. These have all happened. 
ID: hal-02114531

(C) 2019 by Abambres et al. (CC BY 4.0)

\section{6}

We know that the system of peer review is biased, unjust, unaccountable, incomplete, easily fixed, often insulting, usually ignorant, occasionally foolish, and frequently wrong.

Horton (2000) 
ID: hal-02114531

(C) 2019 by Abambres et al. (CC BY 4.0)

\section{6}

In the present study, 75 journal reviewers were asked to referee manuscripts which described identical experimental procedures but which reported positive, negative, mixed, or no results. In addition to showing poor interrater agreement, reviewers were strongly biased against manuscripts which reported results contrary to their theoretical perspective. 
ID: hal-02114531

(C) 2019 by Abambres et al. (CC BY 4.0)

\section{My Proposal}

While preprints may not be new, their growth may well be (Lin 2018): roughly $30 \%$ in the past 2 years, while the article counterpart for the same period was about $1 / 10$ of that value. Crossref, an official Digital Object Identifier (DOI) registration agency of the International DOI Foundation, was launched in early 2000 as a cooperative effort among publishers to enable persistent crosspublisher citation linking in online academic journals. Since 2016, Crossref is accepting the registration of DOIs for preprints (AAAS 2016). The French Society for Ecology and Evolution supports the development of new ways of disseminating scientific knowledge, not based on commercial journals but on open archives and a public peer review process, completely handled by the researchers themselves. In UK, the use of preprints is consistent with the Biotechnology and Biological Sciences Research Council' and the Medial Research Council's commitment to ensure that research committee members, assessment panel members and external reviewers consider the content of research papers rather than rely on venue of formal publication as a quality measure - like advocated by Abambres et al. (2018a). According to Google Scholar, the most highly cited source in Economics is the non-peer-reviewed NBER Working Papers platform, with a h5-index of 165 (Tennant et al. 2018). Recent research shows that preprints shared on bioRxiv gained more online attention and citations than similar journal articles published without preprints (Serghiou and Ioannidis 2018) ${ }^{13}$. Examples of 'highly-cited' (more than 100 citations) preprints can be found in Dimensions - a linked research knowledge system that re-imagines discovery and access to research, developed by Digital Science \& Research Solutions, Inc in collaboration with over 100 leading research organizations worldwide.

Since I'm fully against peer-reviewed publishing, my proposal for scientific / academic dissemination is the use of free eprint ${ }^{14}$ repositories. Fig. 1 shows the ones (with the respective URLs) I highly recommend for you to deposit and disseminate your papers (i) efficiently and effectively, (ii)

13. If you support preprints in the life sciences, you can make it public at We Support Preprints.

14. Also called preprint, but since I am not proposing "printing" the papers via publication in peer-reviewed journals, I'd rather use the term eprint. 
ID: hal-02114531

(C) 2019 by Abambres et al. (CC BY 4.0)

free of any formatting (Qeios is the only exception) or paper length requirements, and (iii) free of any pre-publication peer review - in some of them you can comment/review online any published paper. Moreover, (I) all those platforms can assign a new DOI to each published eprint, (II) some archives (or repositories) are also able to assign an existing DOI, and (III) most (if not all) are Google Scholarindexed (meaning that citations to your eprints will be accounted for in your GS profile - e.g., $\underline{\text { my }}$ profile). The only repository I recommend with some reservations is SSRN ${ }^{15}$ (owned by Elsevier), since according to my experience (most of my submissions are still awaiting approval):

(i) It might take up to 2 months for a single submission to be accepted and published (even though there's no peer-review, some people check its suitability for publication).

(ii) I am not sure if they will accept all submissions within the scope of each SSRN network (as it should be), including controversial opinion papers like this one or Abambres et al. (2018a, b).

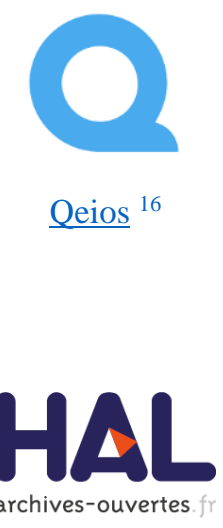

$\underline{\text { HAL }}$

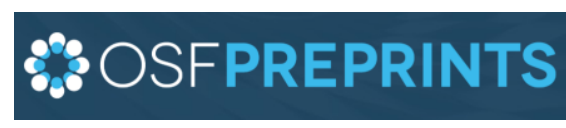

OSF preprints ${ }^{17}$

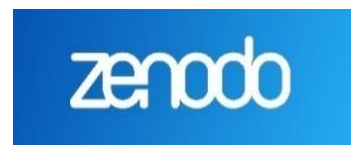

zenodo

\section{ResearchGate}

\author{
$\underline{\text { ResearchGate }}$
}

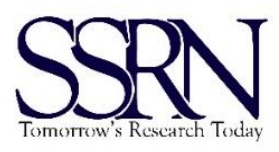

$\underline{\text { SSRN }}$

Fig. 1. Recommended free eprint repositories (all assign DOI).

15. Formerly known as Social Science Research Network, the repository is now venue of tens of distinct networks virtually covering every field of knowledge (social sciences, engineering, life sciences, economics, etc.).

16. Write, publish (with doi) and review/assess research in a single online platform.

17. In Feb 2018, Hypothesis and the Center for Open Science announced their collaboration to bring open annotation to Open Science Framework (OSF) Preprints and the growing community of preprint servers hosted on OSF. The integration of Hypothesis makes it possible to publicly comment any part of the preprint you like (even just a word, phrase or figure). 
ID: hal-02114531

(C) 2019 by Abambres et al. (CC BY 4.0)

My proposal makes it possible to avoid, besides the harmful peer review stage, requirements from publishers to re-write parts of a manuscript that have been copied from published paper(s). But in which conditions has that copying been performed? The author who copy-pastes owns the moral rights of that content, and that is perfectly clear in all aforementioned articles via a section called 'contributions', where the contribution of each author to the paper is specified. Publishers call it "self-plagiarism", which makes no sense to me. If something is mine, I am free to publish it whenever I want with no need to either (i) cite myself, (ii) put copied text between quotes, and/or (iii) re-write copied text using other words.

\subsection{Not Recommended Eprint Repositories}

Not all post-publication peer review platforms are recommendable in my opinion, since some might reject submitted papers, depending on their contents. I have experienced that myself after submitting my eprints Abambres et al. (2018a, b) to both $\underline{\operatorname{Sci}(\mathrm{MDPI})}$ and $\underline{\text { Faculty of } \mathbf{1 0 0 0}}$. Concerning the latter, my works were "made impossible to accept" via the following arguments (in red are my comments):

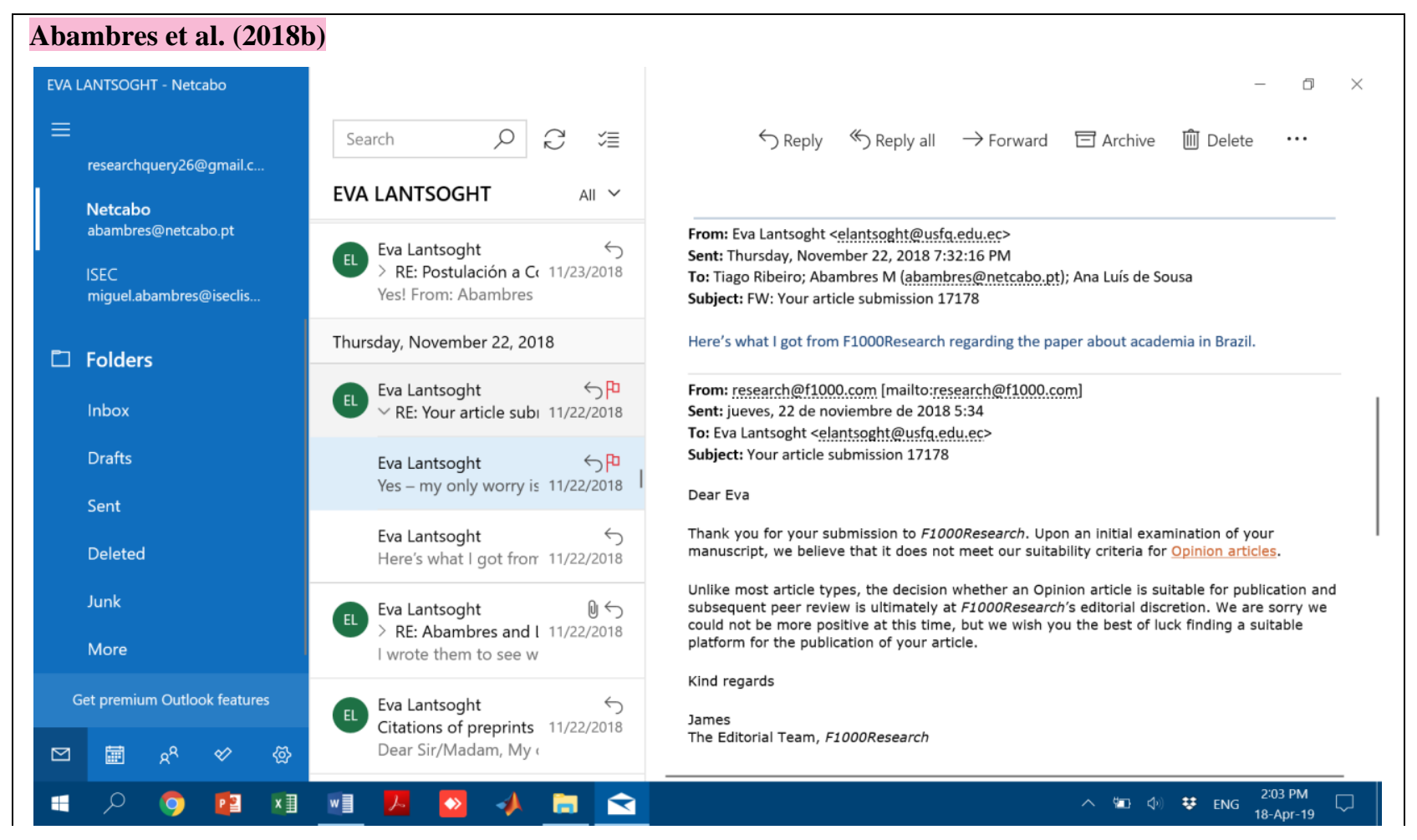


ID: hal-02114531

(C) 2019 by Abambres et al. (CC BY 4.0)

That's not a true post-publication peer review (PPPR) system - true ones accept all submissions within the scope of the platform, making them publicly and freely available for everybody to read and comment.

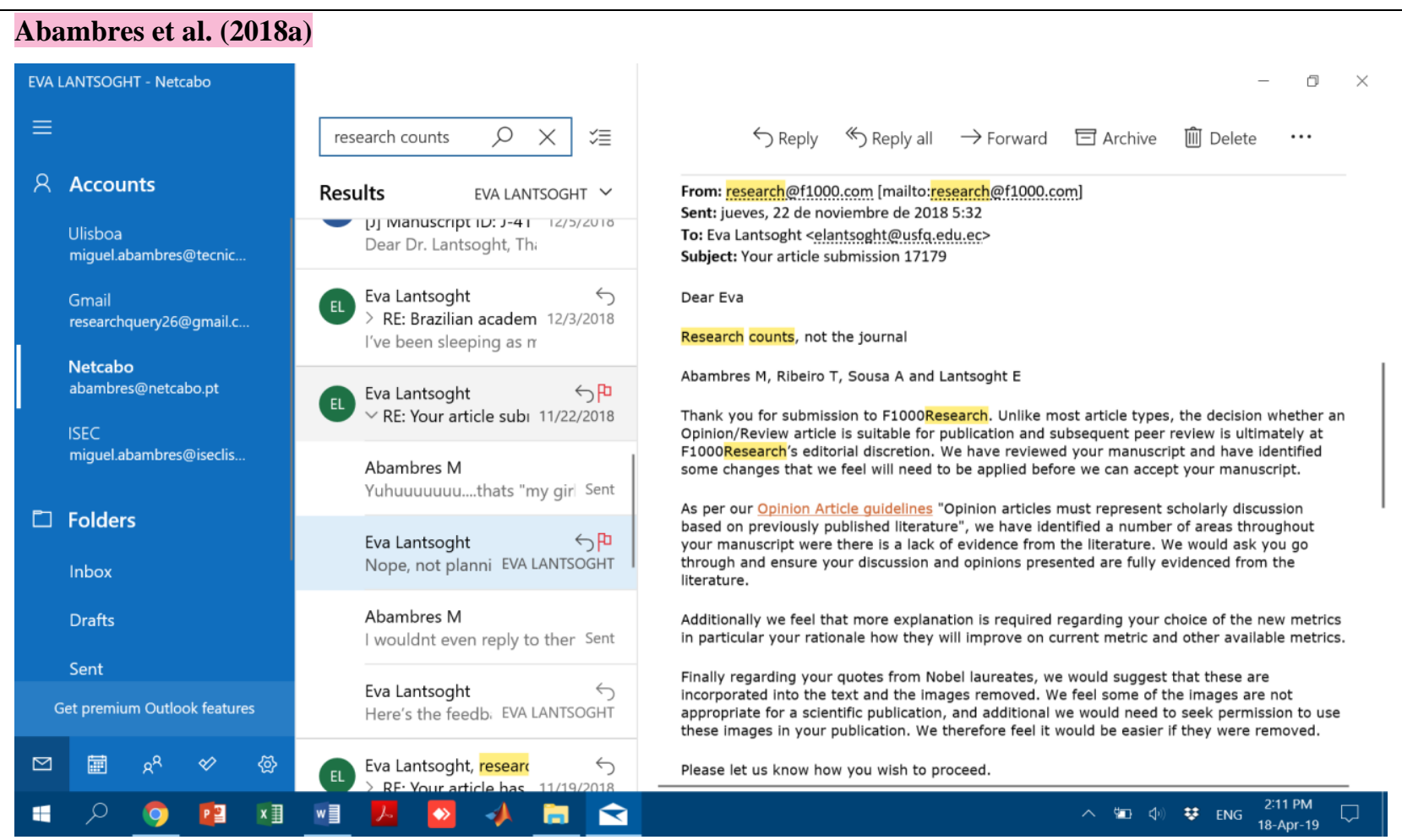

"We have reviewed your manuscript and have identified some changes that we feel will need to be applied before we can accept your manuscript."

For me that's not a true post-publication peer review (PPPR) system - true ones accept all submissions within the scope of the platform, making them publicly and freely available for everybody to read and comment.

"As per our Opinion Article guidelines "Opinion articles must represent scholarly discussion based on previously published literature", we have identified a number of areas throughout your 


\section{ID: hal-02114531}

(C) 2019 by Abambres et al. (CC BY 4.0)

manuscript were there is a lack of evidence from the literature. We would ask you go through and ensure your discussion and opinions presented are fully evidenced from the literature."

That means the authors of the paper cannot present their opinion on a certain subject for the first time (since it was never published before).

"Additionally, we feel that more explanation is required regarding your choice of the new metrics; in particular your rationale how they will improve on current metric and other available metrics."

For me that's not a true PPPR system - true ones accept all submissions within the scope of the platform, making them publicly and freely available for everybody to read and comment.

"Finally, regarding your quotes from Nobel laureates, we would suggest that these are incorporated into the text and the images removed. We feel some of the images are not appropriate for a scientific publication, and additional we would need to seek permission to use these images in your publication. We therefore feel it would be easier if they were removed."

Besides not allowing authors to express their own opinion, they try to create a definition of "scientific publication".

Lastly, I have withdrawn all submissions and performed no changes to the manuscripts. To my eyes, the aforementioned PPPR publishing systems simply ban controversial opinion papers, particularly those criticizing the current state of (i) scientific publishing/assessment (e.g., Abambres et al. 2018a), or (ii) academic/scientific management and meritocracy (e.g., Abambres et al. 2018b).

\subsection{Assessment of Research Impact}

In this section I'm going to make a brief survey as a way to both (i) express my view about the correct way to assess research impact (my answers are highlighted), and (ii) allow each reader to 
ID: hal-02114531

(C) 2019 by Abambres et al. (CC BY 4.0)

build her/his own view by providing several scenarios and possible answers. Before answering the survey in 3.2.2, please carefully go through the short introduction in 3.2.1.

\subsubsection{Brief Considerations}

When to cite a reference / publication in a manuscript? The scholar/scientist adding content from any publication to a manuscript he/she is writing as co-author, for considering that it has a positive impact on the development of that work, has the moral obligation of citing (making reference of) such publication before publishing the manuscript - the only exception is when he/she owns the moral rights of that re-used content, and that is made clear in both the manuscript and the publication. Regardless the number of times one cites that publication within the manuscript, it's said that the former is cited (once) by the latter.

Defining 'Academic/Scientific Impact of a Publication': Recognition of the importance of the publication for the state of art and/or the development of some research work. That recognition is measured, in its simplest and most traditional way, by the total number of citations that publication gets from the literature until a specific date. For the interested reader, although unfortunately (as far as I am concerned) it's not yet implemented by academic/scientific platforms, several metrics are proposed in the literature (check Abambres and Arab 2016) to credit each individual co-author of a publication, i.e. to compute his/her $\%$ of the total number of citations attributed to that publication.

Defining 'Social Impact of a Publication': Recognition of the importance of some publication for the well-being of the society. Such recognition is measured, among other factors, by the quantity of people positively affected (directly or indirectly) by the innovation proposed in that publication. Examples of innovations implemented in a society are:

(a) More effective mathematical models in infrastructure design codes.

(b) Prosthesis models that considerably improve the quality of life of their users. 
(c) Natural medicine that cures some types of cancer in a few months without dangerous side effects and the need of any other treatment.

(d) Novel financial-economic model allowing each nation to erase extreme poverty.

(e) Clinical integration of a therapy that eliminates the need of drugs for depression treatment.

(f) Replacement of all fossil fuel by the ecofriendly biofuel.

(g) New soil and water treatment techniques allowing the sustainable increase of the life span of several animal and vegetable species.

\subsubsection{Survey}

1. How should the quality (positive impact) of a work published by a scholar or scientist be evaluated?

(i) by its scientific/academic and social impact, and also by the international reputation of the means of publication (journal, magazine, repository, book, etc.).

(ii) only by the international reputation of the means of publication (journal, magazine, repository, book, etc.).

(iii) only by its scientific/academic and social impact.

2. A scholar/scientist A publishes a work on economics in an open access repository with no peer review. That publication gets, in the first 10 years, 1000 citations. Moreover, the innovation inherent to that work benefits $90 \%$ of the world population.

A scholar/scientist $\mathbf{B}$ publishes (in the same day as A) a work on economics in the most renowned scientific journal in the field - a peer-reviewed one. That publication gets, in the first 10 years, 10 citations. Moreover, the innovation inherent to that work benefits $1 \%$ of the world population.

In each case (A or B), the number of citations is the number of publications citing that work. Moreover, let's assume all citations in each case come from articles published in the world top five journals in economics. 
Objectively, and based on the data just provided, which work presents higher positive impact (or quality) passed 10 years from its publication?

(i) $\mathrm{A}$

(ii) $\mathrm{B}$

3. Do you believe that every article published in a renowned peer-reviewed journal has necessarily a great academic/scientific and social impact?

(i) Yes

(ii) No (and might not have any impact)

\section{Acknowledgements}

I dedicate this paper to my beloved parents Ana Abambres and José Abambres, mi amor Mony, my cats Tiger and Cheetah, and all those who enjoy and support my work and mindset.

\section{References}

Abambres M, Arab P (2016). Citation Indexes Accounting for Authorship Order in Co-Authored Research - Review and New Proposal. Science \& Technology Libraries, 35(4), doi: 10.1080/0194262X.2016.1242450

Abambres M, Ribeiro T, Sousa A, Lantsoght E (2018a). 'Research Counts, Not the Journal', id: hal02074859

Abambres M, Ribeiro T, Sousa A, Lantsoght E (2018b). Ineffective Obsessions in Brazilian Academia and Proposals Towards Meritocracy, hal-02074849

American Association for the Advancement of Science (AAAS) (2016). Crossref now accepts preprints. Available at URL [Accessed 3 Feb. 2019]. Archived at URL

Bal M (2018). Mieke Bal: Let's Abolish the Peer-Review System. Available at URL [Accessed 6 Feb. 2019]. Archived at URL 
ID: hal-02114531

(C) 2019 by Abambres et al. (CC BY 4.0)

Bancroft D (2017). How PPPR is improving the quality of Science. Available at URL [Accessed 17 Jan. 2019]. Archived at URL

Belluz J, Hoffman S (2015). Let's stop pretending peer review works. Available at URL [Accessed 6 Feb. 2019]. Archived at URL

Bourne PE, Polka JK, Vale RD, Kiley R (2017) Ten simple rules to consider regarding preprint submission. PLoS Comput Biol, 13(5), doi: 10.1371/journal.pcbi.1005473

Carroll AE (2018). Peer Review: The Worst Way to Judge Research, Except for All the Others. Available at URL [Accessed 5 Feb. 2019]. Archived at URL

Chawla DS (2017). When a preprint becomes the final paper. Nature, research highlights: social selection (January 20th), doi: 10.1038/nature.2017.21333.

Colquhoun D (2011). Publish-or-perish: Peer review and the corruption of science. Available at URL [Accessed 19 Feb. 2019]. Archived at URL

Curry S (2015). Peer review, preprints and the speed of science. Available at URL [Accessed 8 Jan. 2019]. Archived at URL

Dzeng E (2014). How Academia and Publishing are Destroying Scientific Innovation: A Conversation with Sydney Brenner. Available at URL [Accessed 20 Feb. 2019]. Archived at $\underline{\mathrm{URL}}$

Einstein A, Berger N, Harris A (2011). The World as I See It (the authorized A. Einstein Archives edition), US: Philosophical Library/Open Road, ISBN: 9781453204948.

Eisen M (2011). Peer review is $\mathrm{f}^{* * *}$ ed up - let's fix it. Available at URL [Accessed 6 Feb. 2019]. Archived at URL

Etkin A, Gaston T, Roberts J (2017). Peer Review: Reform and Renewal in Scientific Publishing. ATG LLC (Media), USA, doi: 10.3998/mpub.9944026. Archived at URL

Haug CJ (2015). Peer-Review Fraud - Hacking the Scientific Publication Process. New England Journal of Medicine, 373(25), doi: 10.1056/nejmp1512330. Archived at URL

Horton R (2000). Genetically modified food: consternation, confusion, and crack-up. Medical Journal of Australia, 172(4), 148-149.

Hunter J (2012). Post-publication peer review: opening up scientific conversation. Frontiers in Computational Neuroscience, 6(63), doi: 10.3389/fncom.2012.00063 
ID: hal-02114531

(C) 2019 by Abambres et al. (CC BY 4.0)

Kriegeskorte N (2009). Open post-publication peer review (full argument). Available at URL [Accessed 5 Feb. 2019]. Archived at URL

Kriegeskorte N, Walther A, Deca D (2012). An emerging consensus for open evaluation:18 visions for the future of scientific publishing. Frontiers in Computational Neuroscience, 6(94), doi: 10.3389/fncom.2012.00094. Archived at URL

Krumholz HM (2015). The End of Journals. Circ Cardiovasc Qual Outcomes, 8(6), doi: 10.1161/circoutcomes.115.002415. Archived at URL

Learn JR (2019). What bioRxiv's first 30,000 preprints reveal about biologists. Nature, News (January 22 ${ }^{\text {nd }}$ ), doi: 10.1038/d41586-019-00199-6. Archived at URL

Lin J (2018). Preprints growth rate ten times higher than journal articles. Available at URL [Accessed 4 Feb. 2019]. Archived at URL

Mahoney MJ (1977). Publication prejudices: An experimental study of confirmatory bias in the peer review system. Cognitive therapy and research, 1(2), doi: 10.1007/BF01173636. Archived at $\underline{\mathrm{URL}}$

Murphy B (2019). Why Scientific Peer Review is a Sham. Available at URL [Accessed 20 Feb. 2019]. Archived at $\underline{\mathrm{URL}}$

Neuen D (2018). Peer-review and publication does not guarantee reliable information - Students 4 Best Evidence. Available at URL [Accessed 5 Feb. 2019]. Archived at URL

O'Grady C (2017). 107 cancer papers retracted due to peer review fraud. Available at URL [Accessed 20 Feb. 2019]. Archived at URL

Packer M (2019). Is Journal Peer-Review Now Just a Game? Medpagetoday.com. Available at URL [Accessed 6 Feb. 2019]. Archived at URL

Peters DP, Ceci SJ (1982). Peer-review practices of psychological journals: The fate of published articles, submitted again. Behavioral and Brain Sciences, 5(2), doi: 10.1017/s0140525x00011183. Archived at $\underline{\mathrm{URL}}$

Peterson GI (2018). Postpublication peer review: A crucial tool, Science, 359(6381), doi: 10.1126/science.aas9490. Archived at $\underline{\mathrm{URL}}$

Polka J (2019). Preprint FAQ. ASAPbio. Available at URL [Accessed 6 Jan. 2019].

Powell K (2016). Does it take too long to publish research? Nature, 530(7589), doi: 10.1038/530148a. Archived at URL 
ID: hal-02114531

(C) 2019 by Abambres et al. (CC BY 4.0)

Ruseckiy A, Mulyarchik M (2018). Peer review: a black sheep in the scientific world? Available at URL [Accessed 20 Feb. 2019]. Archived at URL

Rutherford A (2015). In science we trust... up to a point. Available at URL [Accessed 11 Jan. 2019]. Archived at $\underline{\mathrm{URL}}$

Serghiou S, Ioannidis JPA (2018) Altmetric Scores, Citations, and Publication of Studies Posted as Preprints. JAMA, 319(4), doi: 10.1001/jama.2017.21168. Archived at URL

Shirky C (2008). Here Comes Everybody: The Power of Organizing Without Organizations. PenguinPress, New York, NY. Available at URL

Siler K, Lee K, Bero L (2014). Measuring the effectiveness of scientific gatekeeping. Proceedings of the National Academy of Sciences, 112(2), doi: 10.1073/pnas.1418218112. Archived at URL

Smith R (2006). Peer Review: A Flawed Process at The Heart of Science and Journals. Journal of the Royal Society of Medicine, 99(4), 178-82, doi: 10.1177/014107680609900414. Archived at $\underline{\mathrm{URL}}$

Smith R (2010). Classical peer review: an empty gun. Breast Cancer Research, 12(4), doi: 10.1186/bcr2742. Archived at URL

Spicer A, Roulet T (2014). Hate the peer-review process? Einstein did too. Available at URL [Accessed 20 Feb. 2019]. Archived at URL

Sullivan WJ (2018). Is It Time for Pre-Publication Peer Review to Die? | PLOS SciComm. Available at URL [Accessed 7 Feb. 2019]. Archived at URL

Tennant J, Bauin S, James S, Kant J (2018). The evolving preprint landscape: Introductory report for the Knowledge Exchange working group on preprints. BITSS preprints, May(17), doi: 10.31222/osf.io/796tu.

The Economist (2017). The shackles of scientific journals (and how to cast them off). Available at URL [Accessed 8 Jan. 2019]. Archived at URL

The Intelligent Design and Evolution Awareness Center (IDEAC) (2019). Is Peer-Review a Requirement of Good Science? Available at URL [Accessed 21 Feb. 2019]. Archived at URL

Vosshall L (2018). Leslie B. Vosshall - We support preprints...Available at URL [Accessed 19 April 2019]. Archived at URL 
ID: hal-02114531

(C) 2019 by Abambres et al. (CC BY 4.0)

Zwaan R (2013). Pre-publication Posting and Post-publication Review. Available at URL [Accessed 6 Feb. 2019]. Archived at URL 